Federal Reserve Bank of Minneapolis

Research Department

\title{
Short and Long Interest Rate Targets*
}

\author{
Bernardino Adão, Isabel Correia, \\ and Pedro Teles
}

Working Paper 680

August 2010

\begin{abstract}
We show that short and long nominal interest rates are independent monetary policy instruments. The pegging of both helps solving the problem of multiplicity that arises when only short rates are used as the instrument of policy. A peg of the nominal returns on assets of different maturities is equivalent to a peg of state-contingent interest rates. These are the rates that should be targeted in order to implement unique equilibria. At the zero bound, while it is still possible to target state-contingent interest rates, that is no longer equivalent to the target of the term structure.
\end{abstract}

Keywords: Monetary policy; Monetary policy instruments; Maturities; Short rates; Long rates; Term structure; Multiplicity of equilibria; Sticky prices

JEL: E3, E4, E5

*Adão, Banco de Portugal; Correia, Banco de Portugal, Universidade Catolica Portuguesa and CEPR; Teles, Banco de Portugal, Universidade Catolica Portuguesa, CEPR, and Federal Reserve Bank of Minneapolis. We thank Ben McCallum, Andy Neumeyer, Juan Pablo Nicolini, and participants at the 2010 Bank of Portugal Conference on Monetary Economics, A Conference to Mark Twenty Years of Inflation Targeting at the Reserve Bank of New Zealand, Meetings of the SED, seminars at Luiss U., Oxford U. We gratefully acknowledge financial support of FCT. The views expressed herein are those of the authors and not necessarily those of the Banco de Portugal, the Federal Reserve Bank of Minneapolis, or the Federal Reserve System. 


\section{Introduction}

At the zero bound for the short term nominal interest rate, are there additional monetary policy instruments? If the short rates today are zero, but the long rates are not, can these be lowered? Can monetary policy be conducted with both short and long interest rates? Can the whole term structure of nominal interest rates be targeted? Should the whole term structure be targeted?

These are old questions of recent renewed interest. There is historical evidence that "...a sufficiently determined Fed can peg or cap Treasury bond prices and yields at other than the shortest maturities." ${ }^{1}$ Indeed in the 40's and 50's, before the Federal Reserve-Treasury Accord of 1951, the Fed managed to establish both the rate on the 90-day Treasury bill and a ceiling on the 12-month Treasury certificate. This was achieved without the need to hold a significant share of long maturity bonds. Operation Twist, in the 1960's, was an attempt by the Fed to raise short rates and lower long rates. ${ }^{2}$ More recently, in 2009, the ECB conducted one week, three and six months, and one year, liquidity providing operations at fixed rates. The recent episodes of very low targets for short term rates, in Japan in the last 15 years, in the US in 2003 and $2004,{ }^{3}$ and during the recent financial crisis, ${ }^{4}$ prompted again the policy question of whether a central bank can target both short and long rates, with the hope of lowering the latter, given that the former cannot be lowered.

There is not much literature on this issue. McGough, Rudebusch, and Williams (2005) discuss the possibility of following a Taylor type rule on a long rate, rather than the short rate. Woodford (2005) commenting on McGough et al. argues that there is nothing policy on the long rates can do, that cannot be done with policy on the short rate. Instead, we show that targeting both short and long rates helps implement a unique equilibrium in the large set of competitive equilibria. Short and long term nominal interest rates are independent monetary policy instruments, and they can, and should, both be used as instruments of policy. Interestingly, the zero bound is an exception to the general result. Precisely at the zero bound, when the economy stays there, no matter what, short and long rates are no longer independent instruments, and targeting both does not solve

\footnotetext{
${ }^{1}$ Ben Bernanke in a speech to the National Economists Club in 2002.

${ }^{2}$ See Bernanke (2002).

${ }^{3}$ In June, 2003, the Fed funds rate fell down to the, by then, historical low level of $1 \%$, and remained there for one year.

${ }^{4}$ At the end of 2008, the target for the Fed funds rate reached zero and remained there.
} 
the multiplicity problem. A small deviation from the zero bound, however, allows to recover the results. It is in this sense that the results are general.

The problem of multiplicity of equilibria when the monetary policy instrument is the short term interest rate was first formally addressed by Sargent and Wallace (1975). In an attempt to side step the multiplicity problem, McCallum (1981) proposes an interest rate feedback such that there is a locally determinate equilibria at the expense of multiple explosive solutions. A large literature on local determinacy followed (see Woodford, 2003 among many others ${ }^{5}$ ). Attention was focused on the local determinate equilibrium, and other solutions were ignored on the basis of arbitrary technical restrictions.

There have been various attempts at solving the problem of multiplicity of equilibria under interest rate policy. The fiscal theory of the price level (see Cochrane (2007) for a critical discussion) assumes that tax rates are also exogenous, so that there are additional equilibrium restrictions that can be used to pin down equilibria. In contrast with this literature, we assume throughout the paper that fiscal policy is determined endogenously, in line with the extensive literature on local and global determinacy.

Atkeson, Chari and Kehoe (2009) consider out of equilibrium escape clauses in the spirit of Obstfeld and Rogoff (1983) and Nicolini (1996), and Christiano and Rostagno (2002). The point of Obstfeld and Rogoff and Nicolini was that if some form of convertibility was to be introduced in case prices deviated from some equilibrium, then there would be a unique equilibrium where convertibility would not be used.

While, in general, interest rate feedback rules give rise to multiplicity there are cases of rules that deliver global uniqueness. This has been shown by Loisel (2008) in a linear model and by Adão, Correia and Teles (2009) in standard monetary models.

In this paper, we start by illustrating, using a simple flexible price monetary model, that targeting the return on noncontingent short term bonds can pin down the conditional expectation of inflation but not the distribution of realized inflation across states. If the model was deterministic, given an initial price level, the target for the short term nominal interest rate, would be able to determine the whole path of price levels. Not so, under uncertainty. Even if the classical problem of multiplicity of the initial price level is solved, there is still multiplicity of the distribution of prices across states. The nominal interest rate is a noncontingent

\footnotetext{
${ }^{5}$ Clarida, Gali and Gertler (1999, 2000), Carlstrom and Fuerst (2001, 2002), Benhabib, Schmitt-Grohe and Uribe (2001a), among many others.
} 
return and therefore can only be used to determine expectations of inflation, and not realized inflation. This multiplicity of equilibria is still present if the policy rule is a feedback rule for the short term nominal rate, and it is also present under a money supply rule.

We show that targeting the returns on nominal assets of different maturities can solve the multiplicity of equilibria associated with uncertainty. The intuition is very simple. If monetary policy were to target the returns on state-contingent nominal assets, then given an initial price level, it would be able to pin down the price level in every date and state. Targeting the returns on state-contingent nominal assets is, under certain conditions, equivalent to targeting the returns on assets of different maturities. A necessary condition is that the number of maturities equals the number of possible contingencies. But this is not sufficient. There has to be variability in the noncontingent returns. For this reason, exactly at the zero bound, if the economy was to stay there for any possible contingency, then the equivalence result would not go through. In this case of, mostly theoretical interest, it would be necessary to target the state contingent returns in order to pin down realized inflation rates.

In a flexible price economy, when policy is conducted with interest rate targets, prices are not pinned down but allocations are. Instead, under sticky prices, setting the path for the nominal interest rates not only does not pin down prices, it also generates multiple equilibria in the allocations. We extend the results to a simple sticky price environment.

Our results are related to the results in Nakajima and Polemarchakis (2003), Bloise, Dreze and Polemarchakis (2004). These papers analyze the degrees of multiplicity of equilibria when policy is conducted with a target for the nominal interest rate. In order to be able to count, they consider a finite horizon monetary economy and show that when policy is conducted with a target for the nominal interest rate, the degree of multiplicity is the number of terminal nodes of the event tree. Adão, Correia and Teles (2009) show that the economy with an infinite horizon is not the limit of the finite horizon economy. In particular there are interest rate rules that achieve uniqueness in the infinite horizon economy, that would still lead to multiplicity in the finite horizon economy.

The results are also related to the ones in Angeletos (2002) and Buera and Nicolini (2004) that have shown that state-contingent debt may be replicated by debt of multiple maturities. Their proof is for quantities, ours for prices, but the mechanisms are similar. They also need as many maturities as the number of contingencies. 


\subsection{A preview}

Arbitrage between holding a two period bond to maturity and rolling over one period bonds for two periods implies

$$
R_{t}^{2} E_{t}\left[\frac{u_{C}(t+2)}{P_{t+2}}\right]=R_{t}^{1} E\left[R_{t+1}^{1} E_{t+1}\left[\frac{u_{C}(t+2)}{P_{t+2}}\right]\right],
$$

where $R_{t}^{2}$ is the period $t$ gross compound return on a two-period bond, and $R_{t}^{1}$ and $R_{t+1}^{1}$ are the gross returns on the one-period bond in periods $t$ and $t+1$, respectively. $\frac{u_{C}(t+2)}{P_{t+2}}$ is the marginal utility of one unit of money in period $t+2$. If the covariance between $R_{t+1}^{1}$ and $E_{t+1}\left[\frac{u_{C}(t+2)}{P_{t+2}}\right]$ is zero, then

$$
R_{t}^{2}=R_{t}^{1} E_{t}\left[R_{t+1}^{1}\right],
$$

which is the pure expectations hypothesis of the term structure. The long rate is given by the sequence of short rates. In this case obviously the short and long rates are not independent instruments. Targeting the short rates pins down the long rates.

If the short rate in period $t+1$ is $R_{t+1}^{1}=1$, in every state, corresponding to the zero bound, then the covariance is zero, and setting the short rates at the zero bound, also sets the long rates, at the zero bound. Note that this is not the interesting policy case, where short rates are zero, but long rates are not.

In general the covariance between $R_{t+1}^{1}$ and $E_{t+1}\left[\frac{u_{C}(t+2)}{P_{t+2}}\right]$ is not zero. And it turns out that it is a function of the long rates. Targeting both short and long rates, helps pinning down the covariance, allowing to implement uniquely a desirable process for allocations and prices.

Our approach is very different from the more common approach to implementation, based on local determinacy of equilibria, as in Woodford (2005). According to this, if monetary policy is conducted using an interest rate feedback rule for the short term interest rate, then, under certain conditions, there is a locally determinate equilibrium, and a locally determinate term premium. ${ }^{6}$ At the determinate solution, the long rates are obtained by arbitrage from the short rates. It would not be possible to use both short and long rates if the locally determinate equilibrium was indeed the single equilibrium. But it is not. ${ }^{7}$ The locally determinate

\footnotetext{
${ }^{6}$ This means that the linear system of equations that approximates the equilibrium conditions in the neighborhood of a steady state, has a unique solution in that neighborhood and multiple solutions outside that neighborhood.

${ }^{7}$ See Cochrane (2007) for a general discussion.
} 
equilibrium is only one of the possible equilibria. ${ }^{8}$

\section{A model with flexible prices}

We first consider a simple cash in advance economy with flexible prices. The economy consists of a representative household, a representative firm behaving competitively, and a government. The uncertainty in period $t \geq 0$ is described by the random variable $s_{t} \in S_{t}$, where $S_{t}$ is the set of possible events at $t$, and the history of its realizations up to period $t$ (state or node at $t$ ), $\left(s_{0}, s_{1}, \ldots, s_{t}\right)$, is denoted by $s^{t} \in S^{t}$. We assume that $s_{t}$ has a discrete distribution. The number of states in period $t \geq 0$ is $\Phi_{t}$.

Production uses labor according to a linear technology. We impose a cashin-advance constraint on the households' transactions with the timing structure described in Lucas and Stokey (1983). That is, each period is divided into two subperiods, with the assets market operational in the first subperiod and the goods market in the second.

\subsection{Competitive equilibria}

Households The households have preferences over consumption $C\left(s^{t}\right)$, and leisure $L\left(s^{t}\right)$, described by the expected utility function

$$
U=E_{0}\left\{\sum_{t=0}^{\infty} \beta^{t} u\left(C\left(s^{t}\right), L\left(s^{t}\right)\right)\right\}
$$

where $\beta$ is a discount factor. The households start period $t$, in state $s^{t}$, with nominal wealth $\mathbb{W}\left(s^{t}\right)$. They decide to hold money, $M\left(s^{t}\right)$, and to buy $B^{j}\left(s^{t}\right)$ nominal bonds that pay $R^{j}\left(s^{t}\right) B^{j}\left(s^{t}\right), j=1, \ldots, n$, periods later. $R^{1}\left(s^{t}\right)$ is the gross short term nominal interest rate. They also buy $Z\left(s^{t+1}\right)$ units of state-contingent nominal securities. Each security pays one unit of money at the beginning of period $t+1$ in state $s^{t+1}$. Let $Q\left(s^{t+1} / s^{t}\right)$ be the beginning of period $t$ price of these securities normalized by the probability of the occurrence of the state. The households spend $E_{t} Q\left(s^{t+1} / s^{t}\right) Z\left(s^{t+1}\right)$ in state-contingent nominal securities. Thus, in the

\footnotetext{
${ }^{8}$ See Benhabib, Schmitt-Grohe and Uribe (2001b), Benhabib, Schmitt-Grohe and Uribe (2001b, 2002, 2003) and Schmitt-Grohe and Uribe (2009). They show that the conditions for local determinacy may in fact be conditions for global indeterminacy.
} 
assets market at the beginning of period $t$ they face the constraint

$$
M\left(s^{t}\right)+\sum_{j=1}^{n} B^{j}\left(s^{t}\right)+E_{t} Q\left(s^{t+1} / s^{t}\right) Z\left(s^{t+1}\right) \leq \mathbb{W}\left(s^{t}\right)
$$

where the initial nominal wealth $\mathbb{W}\left(s_{0}\right)$ is given.

Consumption must be purchased with money according to the cash in advance constraint

$$
P\left(s^{t}\right) C\left(s^{t}\right) \leq M\left(s^{t}\right) .
$$

At the end of the period, the households receive the labor income $W\left(s^{t}\right) N\left(s^{t}\right)$, where $N\left(s^{t}\right)=1-L\left(s^{t}\right)$ is labor and $W\left(s^{t}\right)$ is the nominal wage rate and pay lump sum taxes, $T\left(s^{t}\right)$. Thus, the nominal wealth households bring to state $s^{t+1}$ is

$\mathbb{W}\left(s^{t+1}\right)=M\left(s^{t}\right)+\sum_{j=1}^{n} R^{j}\left(s^{t+1-j}\right) B\left(s^{t+1-j}\right)+Z\left(s^{t+1}\right)-P\left(s^{t}\right) C\left(s^{t}\right)+W\left(s^{t}\right) N\left(s^{t}\right)-T\left(s^{t}\right)$

The households' problem is to maximize expected utility (2.1) subject to the restrictions $(2.2),(2.3),(2.4)$, together with a no-Ponzi games condition on the holdings of assets.

The following are first order conditions of the households' problem:

$$
\begin{gathered}
\frac{u_{L}\left(s^{t}\right)}{u_{C}\left(s^{t}\right)}=\frac{W\left(s^{t}\right)}{P\left(s^{t}\right) R^{1}\left(s^{t}\right)}, \\
\frac{u_{C}\left(s^{t}\right)}{P\left(s^{t}\right)}=R^{j}\left(s^{t}\right) E_{t}\left[\frac{\beta^{j} u_{C}\left(s^{t+j}\right)}{P\left(s^{t+j}\right)}\right], j=1, \ldots, n, \\
Q\left(s^{t+1} / s^{t}\right)=\beta \frac{u_{C}\left(s^{t+1}\right)}{u_{C}\left(s^{t}\right)} \frac{P\left(s^{t}\right)}{P\left(s^{t+1}\right)} .
\end{gathered}
$$

From these conditions we get

$$
E_{t} Q\left(s^{t+1} / s^{t}\right)=\frac{1}{R^{1}\left(s^{t}\right)} .
$$

Condition (2.5) sets the intratemporal marginal rate of substitution between leisure and consumption equal to the real wage adjusted for the cost of using 
money, $R^{1}\left(s^{t}\right)$. Condition (2.6) is an intertemporal marginal condition necessary for the optimal choice of risk-free nominal bonds of different maturities. Condition (2.7) determines the price of one unit of money at time $t+1$, for each state $s^{t+1}$, normalized by the conditional probability of occurrence of state $s^{t+1}$, in units of money at time $t$, in state $s^{t}$.

Firms The firms are competitive and prices are flexible. The production function of the representative firm is linear

$$
Y\left(s^{t}\right)=A\left(s^{t}\right) N\left(s^{t}\right)
$$

The equilibrium real wage is

$$
\frac{W\left(s^{t}\right)}{P\left(s^{t}\right)}=A\left(s^{t}\right) .
$$

Government The policy variables are taxes $T\left(s^{t}\right)$, nominal interest rates $R^{j}\left(s^{t}\right)$, state-contingent nominal prices $Q\left(s^{t+1} / s^{t}\right)$, money supplies $M\left(s^{t}\right)$, state-noncontingent public debt $B^{j}\left(s^{t}\right)$ and state-contingent debt $Z\left(s^{t+1}\right)$. The government expenditures, $G_{t}$, are exogenous.

The government budget constraints are

$$
\begin{aligned}
M\left(s^{t}\right)+\sum_{j=1}^{n} B^{j}\left(s^{t}\right)+E_{t} Q\left(s^{t+1} / s^{t}\right) Z\left(s^{t+1}\right) & = \\
M\left(s^{t-1}\right)+\sum_{j=1}^{n} R^{j}\left(s^{t+1-j}\right) B\left(s^{t+1-j}\right)+Z\left(s^{t}\right)+P\left(s^{t-1}\right) G\left(s^{t-1}\right)-T\left(s^{t-1}\right), t & \geq 0
\end{aligned}
$$

together with a no-Ponzi games condition. Let $Q\left(s^{t+1}\right) \equiv Q\left(s^{t+1} / s_{0}\right)$, with $Q\left(s_{0}\right)=1$. If $\lim _{T \rightarrow \infty} E_{t} Q\left(s^{T+1}\right) \mathbb{W}\left(s^{T+1}\right)=0$, the budget constraints can be written as

$$
\begin{aligned}
& \sum_{s=0}^{\infty} E_{t} Q\left(s^{t+s+1} / s^{t}\right)\left[M\left(s^{t+s}\right)\left(R^{1}\left(s^{t+s}\right)-1\right)+T\left(s^{t+s}\right)-P\left(s^{t+s}\right) G\left(s^{t+s}\right)\right] \\
= & \mathbb{W}\left(s^{t}\right)
\end{aligned}
$$


Market clearing The goods and labor market clearing conditions are

$$
C\left(s^{t}\right)+G\left(s^{t}\right)=A\left(s^{t}\right) N\left(s^{t}\right)
$$

and

$$
1-L\left(s^{t}\right)=N\left(s^{t}\right) .
$$

We have already imposed market clearing in the money and asset markets.

Equilibria A competitive equilibrium is a sequence of policy variables, quantities and prices such that the private agents solve their problems given the sequences of policy variables and prices, the budget constraint of the government is satisfied, and markets clear.

The competitive equilibrium conditions for the variables $\left\{C\left(s^{t}\right), L\left(s^{t}\right)\right\}$, and $\left\{R^{j}\left(s^{t}\right) \geq 1, Q\left(s^{t+1} / s^{t}\right), M\left(s^{t}\right), B^{j}\left(s^{t}\right), Z\left(s^{t+1}\right), T\left(s^{t}\right)\right\}$ are the resource constraints

$$
C\left(s^{t}\right)+G\left(s^{t}\right)=A\left(s^{t}\right)\left(1-L\left(s^{t}\right)\right),
$$

the intratemporal conditions

$$
\frac{u_{C}\left(s^{t}\right)}{u_{L}\left(s^{t}\right)}=\frac{R^{1}\left(s^{t}\right)}{A\left(s^{t}\right)},
$$

that are obtained from the households intratemporal conditions (2.5) and the firms optimal condition (2.9), as well as the cash in advance constraints (2.3), the intertemporal conditions (2.6) and (2.7), the budget constraints (2.10).

The equations identified above determine a set of equilibrium allocations, prices and policy variables. In order for a particular equilibrium in this set to be implemented, it is necessary to determine exogenous policy rules for a subset of the policy variables.

In the next section we will show that, if interest rates are set exogenously in every date and state, there is multiplicity under uncertainty. The appropriate policy instruments, that allow to implement a unique equilibrium, are the returns on state-contingent nominal assets.

\subsection{Multiplicity of equilibria with interest rate policy}

We start by showing that if the policy instrument is the short term nominal interest rate, given an initial price level, it is possible to implement a unique 
equilibrium in the deterministic economy, but not under uncertainty. From the resource constraints, (2.11) and the intratemporal conditions (2.12), we can write consumption and leisure as functions of the short term nominal rate, $C\left(R^{1}\left(s^{t}\right)\right)$ and $L\left(R^{1}\left(s^{t}\right)\right)$. The system of equations can then be summarized by the following dynamic equations:

$\frac{u_{C}\left(C\left(R^{1}\left(s^{t}\right)\right), L\left(R^{1}\left(s^{t}\right)\right)\right)}{P\left(s^{t}\right)}=\beta R^{1}\left(s^{t}\right) E_{t}\left[\frac{u_{C}\left(C\left(R^{1}\left(s^{t+1}\right)\right), L\left(R^{1}\left(s^{t+1}\right)\right)\right)}{P\left(s^{t+1}\right)}\right], t \geq 0$

together with the cash in advance constraints, (2.3), and the budget constraints, (2.10).

Suppose the short term nominal interest rate $R^{1}\left(s^{t}\right)$ is set exogenously in every date and state. The allocation is then pinned down uniquely. Given the process for $R^{1}\left(s^{t}\right)$, the allocation is obtained from the functions $C\left(R^{1}\left(s^{t}\right)\right)$ and $L\left(R^{1}\left(s^{t}\right)\right)$. The issue is how can a unique sequence of prices levels be pinned down. If there was no uncertainty, given an initial price level, the intertemporal conditions (2.13) would determine the price level uniquely for every date $t \geq 1$. Instead, under uncertainty, even if the initial price level is given, there are still multiple equilibria for the price level in each state.

To see this, notice that in any period $t \geq 1$, given $P\left(s^{t-1}\right)$, there are $\Phi_{t-1}$ equations to determine $\Phi_{t}$ variables, $P\left(s^{t}\right)$. More specifically, for each state $s^{t-1}$, there is one equation to determine $\# S_{t}$ variables, where $\# S_{t}$ is the number of possible events at $t$. Except for the deterministic case, there are multiple solutions for the price level.

The indeterminacy of the initial price level in the deterministic economy is replaced by the indeterminacy of one price level per history, under uncertainty. As we will see below this explosion in degrees of multiplicity under uncertainty results from pegging the noncontingent nominal interest rate instead of the statecontingent nominal returns. If, instead, these were pegged, there would be a single degree of multiplicity as in the deterministic case.

As mentioned before, an interest rate feedback rule does not solve this multiplicity problem. ${ }^{9}$ And neither does a money supply rule. Under certain conditions, there is a locally determinate equilibrium, but, globally, there are still many equilibria.

\footnotetext{
${ }^{9}$ The rules in Adão et al. (2009) and Loisel (2009) are exceptions.
} 


\subsection{Policy with state-contingent interest rates}

In this section we show that a policy that pegs the state-contingent nominal returns, as well as the money supply in the initial period, implements a unique equilibrium.

The equilibrium conditions are the resource constraint, (2.11), the intratemporal condition (2.12), the cash in advance constraints (2.3), the intertemporal conditions (2.6) and (2.7), as well as the budget constraints (2.10).

As before, from the resource constraints (2.11) and the intratemporal condition (2.12) we obtain the functions $C\left(R^{1}\left(s^{t}\right)\right)$ and $L\left(R^{1}\left(s^{t}\right)\right)$.

The system of equilibrium conditions can be summarized by the following dynamic equations:

$$
Q\left(s^{t} / s^{t-1}\right)=\beta \frac{u_{C}\left(R^{1}\left(s^{t}\right)\right)}{u_{C}\left(R^{1}\left(s^{t-1}\right)\right)} \frac{P\left(s^{t-1}\right)}{P\left(s^{t}\right)}, t \geq 1
$$

together with (2.8), the cash in advance condition, (2.3), and the budget constraint that determines, not uniquely, the endogenous taxes and debt levels, (2.10).

Clearly if policy is conducted by setting exogenously the state-contingent nominal interest rates, given the initial price level, the price levels, for every date and state, are all determined. The proposition follows:

Proposition 2.1. If the state-contingent interest rates are set exogenously for every date and state, given an initial price level, there is a unique equilibrium for the allocations and prices.

Proof: Let $P\left(s_{0}\right)$ be given. Given the values for $Q\left(s^{t} / s^{t-1}\right), t \geq 1, R^{1}\left(s^{t}\right)$, $t \geq 0$ are determined uniquely, and given $P\left(s^{t-1}\right), P\left(s^{t}\right)$ is obtained from the intertemporal conditions (2.14) for $t \geq 1$. The conditions only hold for $t \geq 1$. Cannot use the condition at $t=0$, to determine $P\left(s_{0}\right) . M\left(s_{0}\right)$ could pin down the initial price from the cash-in-advance constraint that, if $R^{1}\left(s_{0}\right)>1$, holds with equality.

In these economies there is a unique equilibrium if monetary policy targets the nominal returns on the state-contingent nominal assets and in addition money supply is set exogenously in the initial period.

\subsubsection{State-contingent debt in zero net supply}

Even if the government stands ready to supply and demand any quantity of statecontingent bonds at given state-contingent prices, these assets can be in zero net 
supply in every equilibrium. To see this notice that, when the supply of statecontingent assets is zero, $Z\left(s^{t+1}\right)=0$, the budget constraints of the government are

$$
\begin{aligned}
& \sum_{s=0}^{\infty} E_{t} Q\left(s^{t+s+1} / s^{t}\right)\left[M\left(s^{t+s}\right)\left(R^{1}\left(s^{t+s}\right)-1\right)+T\left(s^{t+s}\right)-P\left(s^{t+s}\right) G\left(s^{t+s}\right)\right] \\
= & \mathbb{W}\left(s^{t}\right)
\end{aligned}
$$

where, with $Z\left(s^{t}\right)=0, \mathbb{W}\left(s^{t}\right)=M\left(s^{t-1}\right)+\sum_{j=1}^{n} R^{j}\left(s^{t+1-j}\right) B\left(s^{t+1-j}\right)+P\left(s^{t-1}\right) G\left(s^{t-1}\right)-$ $T\left(s^{t-1}\right)$ is noncontingent. This must be satisfied for any allocation and prices, at any period and state. Even with $Z\left(s^{t}\right)=0$, there are still multiple solutions of these equations for the endogenous nominal noncontingent debt and the lump sum taxes.

\section{The term structure}

In this section we show the second main result of the paper, that there is an equivalence between pegging state-contingent prices and noncontingent interest rates for different maturities.

In order to illustrate the results that we will derive more generally below, we consider that in each period there are two possible events, $s_{t} \in\{h, l\}, t \geq 1$, and suppose that there are one and two period noncontingent bonds. Then the following conditions must be satisfied:

$$
\begin{gathered}
\frac{u_{C}\left(R^{1}\left(s^{t}\right)\right)}{P\left(s^{t}\right)}=\beta R^{1}\left(s^{t}\right)\left[\pi\left(h / s^{t}\right) \frac{u_{C}\left(R^{1}\left(s^{t}, h\right)\right)}{P\left(s^{t}, h\right)}+\pi\left(l / s^{t}\right) \frac{u_{C}\left(R^{1}\left(s^{t}, l\right)\right)}{P\left(s^{t}, l\right)}\right] \\
\frac{u_{C}\left(R^{1}\left(s^{t}\right)\right)}{P\left(s^{t}\right)} \\
=\beta^{2} R^{2}\left(s^{t}\right)\left[\begin{array}{l}
\pi\left((h, h) / s^{t}\right) \frac{u_{C}\left(R^{1}\left(s^{t}, h, h\right)\right)}{P\left(s^{t}, h, h\right)}+\pi\left((h, l) / s^{t}\right) \frac{u_{C}\left(R^{1}\left(s^{t}, h, l\right)\right)}{P\left(s^{t}, h, l\right)} \\
+\pi\left((l, h) / s^{t}\right) \frac{u_{C}\left(R^{1}\left(s^{t}, l, h\right)\right)}{P\left(s^{t}, l, h\right)}+\pi\left((l, l) / s^{t}\right) \frac{u_{C}\left(R^{1}\left(s^{t}, l, l\right)\right)}{P\left(s^{t}, l, l\right)}
\end{array}\right]
\end{gathered}
$$




$$
\begin{aligned}
& \frac{u_{C}\left(R^{1}\left(s^{t}, h\right)\right)}{P\left(s^{t}, h\right)} \\
= & \beta R^{1}\left(s^{t}, h\right)\left[\pi\left(h /\left(s^{t}, h\right)\right) \frac{u_{C}\left(R^{1}\left(s^{t}, h, h\right)\right)}{P\left(s^{t}, h, h\right)}+\pi\left(l /\left(s^{t}, h\right)\right) \frac{u_{C}\left(R^{1}\left(s^{t}, h, l\right)\right)}{P\left(s^{t}, h, l\right)}\right] \\
& \frac{u_{C}\left(R^{1}\left(s^{t}, l\right)\right)}{P\left(s^{t}, l\right)} \\
= & \beta R^{1}\left(s^{t}, l\right)\left[\pi\left(h /\left(s^{t}, l\right)\right) \frac{u_{C}\left(R^{1}\left(s^{t}, l, h\right)\right)}{P\left(s^{t}, l, h\right)}+\pi\left(l /\left(s^{t}, l\right)\right) \frac{u_{C}\left(R^{1}\left(s^{t}, l, l\right)\right)}{P\left(s^{t}, l, l\right)}\right]
\end{aligned}
$$

The last three conditions, (3.2), (3.3), and (3.4), can be used to obtain

$$
\begin{aligned}
& \frac{u_{C}\left(R^{1}\left(s^{t}\right)\right)}{P\left(s^{t}\right)} \\
= & \beta^{2} R^{2}\left(s^{t}\right)\left[\pi\left(h / s^{t}\right) \frac{u_{C}\left(R^{1}\left(s^{t}, h\right)\right)}{\beta R^{1}\left(s^{t}, h\right) P\left(s^{t}, h\right)}+\pi\left(l / s^{t}\right) \frac{u_{C}\left(R^{1}\left(s^{t}, l\right)\right)}{\beta R^{1}\left(s^{t}, l\right) P\left(s^{t}, l\right)}\right]
\end{aligned}
$$

Given $P\left(s^{t}\right)$, conditions (3.1) and (3.5) determine $P\left(s^{t}, h\right)$ and $P\left(s^{t}, l\right)$, provided $R^{1}\left(s^{t}, h\right) \neq R^{1}\left(s^{t}, l\right)$. It follows that if $R^{1}\left(s^{t}\right)$ and $R^{2}\left(s^{t}\right)$ are set exogenously, and $R^{1}\left(s^{t}, h\right) \neq R^{1}\left(s^{t}, l\right)$, for all $s^{t}$, for a given initial price level $P\left(s_{0}\right)$, there is a unique solution for the allocations and prices.

Conditions (3.1) and (3.5), are two linear equations in two unknowns, the inverse of the price levels in the two states. As long as the matrix of coefficients is invertible there is a single solution. In order for that to be the case it must be that the two rates $R^{1}\left(s^{t}, h\right)$ and $R^{1}\left(s^{t}, l\right)$ are different, but they can differ by an arbitrarily small number. In this sense, the conditions for the invertibility of the matrix are general.

The number of maturities cannot be lower than the number of possible events. For the general case with $n$ contingencies, the $n \times n$ matrix must also be invertible, but that condition holds generally. The proposition follows.

Proposition 3.1. Let $S_{t}=\left\{s_{1}, s_{2}, \ldots, s_{n}\right\}$ and suppose there are nominal noncontingent assets of maturity $j=1, \ldots, n$. If the returns on these assets are set exogenously, then, in general, there is a unique equilibrium for the allocations and prices, given the initial price level $P\left(s_{0}\right)$. 
Proof: See Appendix 1.

Corollary 3.2. Short and long term nominal interest rates are independent monetary policy instruments.

Other than in the deterministic case, when the number of contingencies is $n \geq 2$, short and long rates are independent monetary policy instruments. As $n$ becomes arbitrarily large, the whole term structure can be pegged.

\subsection{The zero bound}

While the question of using long rates as an instrument of policy is typically raised when short rates are very close to the zero lower bound, it turns out that, at the zero bound, the conditions for the result in proposition 3.1 may not be verified.

If the economy was always at the zero bound, then $R^{1}\left(s^{t}, h\right)=R^{1}\left(s^{t}, l\right)=1$, and it follows that $R^{2}\left(s^{t}\right)=1$. The condition of enough variability in the interest rates is not fulfilled. Short and long rates are not independent policy instruments.

It is possible for the nominal interest rate to be temporarily at the zero bound and there be enough variability in future rates, so that the proposition still holds. Furthermore, the variability in interest rates that is necessary is arbitrarily small, so in that sense the results are robust.

\section{Price setting restrictions}

In this section we show that the results derived above extend to an environment with sticky prices. We modify the environment to consider price setting restrictions. There is, now, a continuum of goods, indexed by $i \in[0,1]$. Each good $i$ is produced by a different firm. The firms are monopolistic competitive and set prices in advance with different lags.

The households have preferences described by $(2.5)$ where $C\left(s^{t}\right)$ is now the composite consumption

$$
C\left(s^{t}\right)=\left[\int_{0}^{1} c_{i}\left(s^{t}\right)^{\frac{\theta-1}{\theta}} d i\right]^{\frac{\theta}{\theta-1}}, \theta>1 .
$$

Households have a demand function for each good given by

$$
c_{i}\left(s^{t}\right)=\left(\frac{p_{i}\left(s^{t}\right)}{P\left(s^{t}\right)}\right)^{-\theta} C\left(s^{t}\right),
$$


where $P\left(s^{t}\right)$ is the price level,

$$
P\left(s^{t}\right)=\left[\int p_{i}^{1-\theta}\left(s^{t}\right) d i\right]^{\frac{1}{1-\theta}} .
$$

The households' intertemporal and intratemporal conditions are as before, (2.5), (2.6) and (2.7).

The government must finance an exogenous path of government purchases $\left\{G\left(s^{t}\right)\right\}_{t=0}^{\infty}$, such that

$$
G\left(s^{t}\right)=\left[\int_{0}^{1} g_{i}^{\frac{\theta-1}{\theta}}\left(s^{t}\right) d i\right]^{\frac{\theta}{\theta-1}}
$$

Given the prices on each good $i$ in units of money, $p_{i}\left(s^{t}\right)$, the government minimizes expenditure on government purchases by deciding according to

$$
\frac{g_{i}\left(s^{t}\right)}{G\left(s^{t}\right)}=\left(\frac{p_{i}\left(s^{t}\right)}{P\left(s^{t}\right)}\right)^{-\theta}
$$

Aggregate resource constraints can be written as

$$
\left(C\left(s^{t}\right)+G\left(s^{t}\right)\right) \int_{0}^{1}\left(\frac{p_{i}\left(s^{t}\right)}{P\left(s^{t}\right)}\right)^{-\theta} d i=A\left(s^{t}\right) N\left(s^{t}\right) .
$$

A fraction $\alpha_{j}$ firms set prices $j$ periods in advance with $j=0, \ldots, J-1$. Firms decide the price for period $t$ with the information up to period $t-j$ to maximize:

$$
E_{t-j}\left[Q\left(s^{t+1} / s^{t-j}\right)\left(p_{i}\left(s^{t}\right) y_{i}\left(s^{t}\right)-W\left(s^{t}\right) n_{i}\left(s^{t}\right)\right)\right]
$$

subject to the production function

$$
y_{i}\left(s^{t}\right) \leq A_{t} n_{i}\left(s^{t}\right)
$$

and the demand function

$$
y_{i}\left(s^{t}\right)=\left(\frac{p_{i}\left(s^{t}\right)}{P\left(s^{t}\right)}\right)^{-\theta} Y\left(s^{t}\right)
$$

where $y_{i}\left(s^{t}\right)=c_{i}\left(s^{t}\right)+g_{i}\left(s^{t}\right)$ 
The optimal price is

$$
p_{i}\left(s^{t}\right)=p_{j}\left(s^{t}\right)=\frac{\theta}{(\theta-1)} E_{t-j}\left[\eta_{j}\left(s^{t+1}\right) \frac{W\left(s^{t}\right)}{A\left(s^{t}\right)}\right]
$$

where $\eta_{j}\left(s^{t+1}\right)=\frac{Q\left(s^{t+1} / s^{t-j}\right) P\left(s^{t}\right)^{\theta} Y\left(s^{t}\right)}{E_{t-j}\left[Q\left(s^{t+1} / s^{t-j}\right) P\left(s^{t}\right)^{\theta} Y\left(s^{t}\right)\right]}$.

Compared with the equilibrium conditions under flexible prices, the set of equilibrium conditions when prices are set in advance includes more variables, the prices of the different firms, but it also includes more restrictions, the price setting restrictions. The number of additional variables and restrictions is the same, and the degrees of freedom are the same as under flexible prices. The degree of indeterminacy is the same as under flexible prices and therefore the result in proposition 2.1, that a peg of state-contingent interest rates delivers a unique equilibrium, still holds when prices are set in advance.

Substituting the state-contingent prices $Q\left(s^{t+1} / s^{t-j}\right)$ in the price setting conditions (4.6), and using the intertemporal condition (2.6) as well as the households' intratemporal condition (2.5), we obtain the intratemporal conditions ${ }^{10}$

$$
E_{t-j}\left[\begin{array}{c}
\frac{u_{C}\left(s^{t}\right)}{R^{1}\left(s^{t}\right)} P\left(s^{t}\right)^{\theta-1} A\left(s^{t}\right)\left(1-L\left(s^{t}\right)\right)- \\
\frac{\theta}{(\theta-1)} u_{L}\left(s^{t}\right) P\left(s^{t}\right)^{\theta-1}\left(1-L\left(s^{t}\right)\right) \frac{P\left(s^{t}\right)}{p_{j}\left(s^{t}\right)}
\end{array}\right]=0, j=0, \ldots J-1 .
$$

The equilibrium conditions can then be summarized by the intertemporal conditions (2.7) and (2.8), the intratemporal conditions (4.8), as well as the conditions for the price level at date $t$, in state $\left(s^{t}\right)$ that can be written as

$$
P\left(s^{t}\right)=\left[\sum_{j=0}^{J-1} \alpha_{j}\left(p_{j}\left(s^{t}\right)\right)^{1-\theta}\right]^{\frac{1}{1-\theta}}
$$

and the resource constraints, written as

$$
\left[C\left(s^{t}\right)+G\left(s^{t}\right)\right] \sum_{j=0}^{J-1} \alpha_{j}\left(\frac{p_{j}\left(s^{t}\right)}{P\left(s^{t}\right)}\right)^{-\theta}=A\left(s^{t}\right) N\left(s^{t}\right) .
$$

\footnotetext{
${ }^{10}$ Notice that, if $J=1$, meaning that there are only flexible price firms, $p_{0}\left(s^{t}\right)=P\left(s^{t}\right)$ and we would get the intratemporal condition obtained under flexible prices,

$$
\frac{u_{C}\left(s^{t}\right)}{u_{L}\left(s^{t}\right)}=\frac{\theta R\left(s^{t}\right)}{(\theta-1) A\left(s^{t}\right)},
$$

corresponding to (2.12), for the case where $\theta \rightarrow \infty$.
} 
The proposition follows:

Proposition 4.1. In the environment with prices set in advance, if the statecontingent interest rates are set exogenously for every date and state, and the money supply is set exogenously in the initial period, there is a unique equilibrium for the allocations and prices.

Proof: Let $\left\{Q\left(s^{t+1} / s^{t}\right), t \geq 0\right\}$ be set exogenously. Then $\left\{R^{1}\left(s^{t}\right), t \geq 0\right\}$ are determined uniquely by (2.8).

At any $t \geq J$, given $P\left(s^{t-1}\right), C\left(s^{t-1}\right)$ and $L\left(s^{t-1}\right)$ there are $\Phi_{t}$ intertemporal conditions, (2.7), $\Phi_{t}$ resource constraints, (4.10), $\Phi_{t}$ price level conditions, (4.9), $\Phi_{t-j}$ price setting conditions, $j=0, \ldots, J-1$, (4.8). The variables are $\Phi_{t}$ consumption levels $C\left(s^{t}\right), \Phi_{t}$ levels of leisure $L\left(s^{t}\right), \Phi_{t}$ price levels and $\Phi_{t-j}$ prices for the different types of firms, $j=0, \ldots, J-1$.

For $t=0$, there is one price level condition, one resource constraint, one price setting condition. The variables are $C\left(s_{0}\right), L\left(s_{0}\right), P\left(s_{0}\right)$ and one price for the flexible firms in period 0. The other prices are historical. Can use the cash in advance constraint with exogenous $M_{0}$ to determine all the variables in period 0 .

For $t=1$, given $P\left(s_{0}\right), C\left(s_{0}\right)$ and $L\left(s_{0}\right)$, there are $\Phi_{1}$ price level conditions, $\Phi_{1}$ resource constraints, $\Phi_{1}+\Phi_{0}$ price setting conditions, $\Phi_{0}$ intertemporal conditions to determine the same number of variables. The variables are $\Phi_{1}$ consumptions $C\left(s^{1}\right), \Phi_{1}$ levels of leisure $L\left(s^{1}\right), \Phi_{1}$ price levels, $\Phi_{1}$ prices for the flexible firms in period 1 and $\Phi_{0}$ prices for the firms setting the price in period 0 for period 1 . Similarly for any period $1 \leq t \leq J-1$.

Also in this environment targeting the term structure of interest rates is equivalent to targeting the state-contingent interest rates. Notice that the number of intertemporal conditions for the state-contingent assets (2.7) is the same as the number of intertemporal conditions for noncontingent assets of different maturities (2.6), when the number of maturities is equal to the number of events.

\section{Concluding Remarks}

We make two major points in this paper. The first, of particular interest for policy, that a central bank can independently target short and long nominal interest

rates, possibly the whole term structure of nominal interest rates. The second, of more theoretical interest, that setting both short and long nominal interest rates allows to solve the problem of multiplicity of equilibria associated with uncertainty, 
that arises when monetary policy is conducted with an interest rate rule for the noncontingent, short-term, nominal interest rate.

We show that the target of the term structure is equivalent, under general conditions, to the target of the state-contingent nominal returns. A monetary policy that targets those returns is able to implement a unique equilibrium, for a given initial price level. This is the case, whether prices are flexible or sticky.

Interestingly, it is precisely at the zero bound, when there is particular interest for alternative policy instruments, that our equivalence result breaks down. At the zero bound, if the economy was to stay there, no matter what, the long rates would have to be equal to the short rates and they would all be zero. Targeting different maturities would not solve the multiplicity problem. A target of the state contingent interest rates would have to be used to implement a unique equilibrium at the, consistently optimal, Friedman rule of zero nominal interest rates. An arbitrarily small deviation from the Friedman rule would, however, allow to recover the equivalence result. 


\section{References}

[1] Adão, Bernardino, Isabel Correia and Pedro Teles, 2009, "Unique Monetary Equilibria with Interest Rate Rules," forthcoming Review of Economic Dynamics.

[2] Angeletos, George-Marios, 2002, "Fiscal Policy with Non-Contingent Debt and the Optimal Maturity Structure," Quarterly Journal of Economics $117,2$.

[3] Atkeson, Andrew, V.V. Chari, Patrick J. Kehoe, 2009, "Sophisticated Monetary Policies," FRB of Minneapolis Staff Report 419.

[4] Benhabib, J., S. Schmitt-Grohe and M. Uribe, 2001a, "Monetary Policy and Multiple Equilibria," American Economy Review 91, 167-185.

[5] Benhabib, J., S. Schmitt-Grohe and M. Uribe, 2001b, "The Perils of Taylor Rules," Journal of Economic Theory 96, 40-69.

[6] Benhabib, J., S. Schmitt-Grohe and M. Uribe, 2002, "Chaotic Interest Rate Rules", American Economic Review 92, 72-78.

[7] Benhabib, J., S. Schmitt-Grohe and M. Uribe, 2003, "Backward Looking Interest Rate Rules, Interest Rate Smoothing and Macroeconomic Stability", Journal of Money, Credit, and Banking 35, 1379-1412.

[8] Bernanke, Ben S., 2002, "Deflation: Making Sure 'It' Doesn't Happen Here," remarks before the National Economists' Club, Washington, D.C., November 21, 2002.

[9] Bloise, G., J. H. Dreze and H. M. Polemarchakis, 2004, "Monetary Equilibria over an Infinite Horizon," mimeo, Brown University.

[10] Buera, Francisco and Juan Pablo Nicolini, 2004, "Optimal Maturity of Government Debt without State Contingent Bonds," Journal of Monetary Economics 51, 3, 531-554.

[11] Carlstrom, Charles T. and Timothy S., 2001, "Timing and Real Indeterminacy in Monetary Models," Journal of Monetary Economics 47, 285-298.

[12] Carlstrom, Charles T. and Timothy S., 2002, "Taylor Rules in a Model that Satisfies the Natural Rate Hypothesis," American Economic Review 92, 79-84.

[13] Christiano, Lawrence and M. Rostagno, 2001, "Money Growth, Monitoring and the Taylor Rule," mimeo, Northwestern University. 
[14] Clarida, Richard, J. Gali and Mark Gertler, 1999, "The Science of Monetary Policy: A New Keynesian Perspective", Journal of Economic Literature 37, 1661-1707.

[15] Clarida, Richard, J. Gali and Mark Gertler, 2000, "Monetary Policy Rules and Macroeconomic Stability: Evidence and Some Theory," Quarterly Journal of Economics 115, 147-180.

[16] Cochrane, John H., 2007, "Inflation Determination with Taylor Rules: A Critical Review," mimeo, The University of Chicago.

[17] Loisel, Olivier, 2009, "Bubble Free Interest Rate Rules," Journal of Economic Theory 144, 4, 1521-1559.

[18] McCallum, Bennett, 1981, "Price Level Determinacy with an Interest Rate Policy Rule and Rational Expectations," Journal of Monetary Economics 8, 319-329.

[19] McGough, Bruce, Glenn D. Rudebusch, John Williams, "Using a Long-Term Interest Rate as the Monetary Policy Instrument," Journal of Monetary Economics 52, 5, 855-879.

[20] Nakajima, Tomoyuki and Herakles Polemarchakis, 2003, "Money and Prices Under Uncertainty," Review of Economic Studies 72, 1, 223-246.

[21] Nicolini, Juan Pablo, 1996, "Ruling Out Speculative Hyperinflations: The Role of the Government," Journal of Economic Dynamics and Control 20, 5, 791-809.

[22] Obstfeld, Maury, and Kenneth Rogoff, 1983, "Speculative Hyperinflations in Maximizing Models: Can We Rule Them Out?", Journal of Political Economy 91, 4, 675-687.

[23] Sargent, Thomas J. and Neil Wallace, 1975, "Rational Expectations, the Optimal Monetary Instrument, and the Optimal Money Supply Rule," Journal of Political Economy 83, 241-254.

[24] Schmitt-Grohe, S., and M. Uribe, 2009, "Liquidity Traps with Global Taylor Rules," International Journal of Economic Theory 5, 85-106..

[25] Woodford, Michael, 2003, "Interest and Prices," Princeton University Press.

[26] Woodford, Michael, 2005, "Comment on Using a Long-Term Interest Rate as the Monetary Policy Instrument," Journal of Monetary Economics 52, 5, 881-887. 


\section{A. Appendix}

\section{A.1. Proposition 3.1}

Let $S_{t}=\left\{s_{1}, s_{2}, \ldots, s_{n}\right\}$. Then it must be the case that

$$
\begin{aligned}
& \frac{u_{C}\left(R^{1}\left(s^{t}\right)\right)}{P\left(s^{t}\right)}=\beta R^{1}\left(s^{t}\right)\left[\begin{array}{c}
\pi\left(s_{1} \mid s^{t}\right) \frac{u_{C}\left(R^{1}\left(s^{t}, s_{1}\right)\right)}{P\left(s^{t}, s_{1}\right)}+\pi\left(s_{2} \mid s^{t}\right) \frac{u_{C}\left(R^{1}\left(s^{t}, s_{2}\right)\right)}{P\left(s^{t}, s_{2}\right)}+ \\
\ldots+\pi\left(s_{n} \mid s^{t}\right) \frac{u_{C}\left(R^{1}\left(s^{t}, s_{n}\right)\right)}{P\left(s^{t}, s_{n}\right)}
\end{array}\right] \\
& \frac{u_{C}\left(R^{1}\left(s^{t}\right)\right)}{P\left(s^{t}\right)}=\beta^{2} R^{2}\left(s^{t}\right)\left[\begin{array}{c}
\pi\left(s_{1} \mid s^{t}\right) \frac{u_{C}\left(R^{1}\left(s^{t}, s_{1}\right)\right)}{\beta R^{1}\left(s^{t}, s_{1}\right) P\left(s^{t}, s_{1}\right)}+\pi\left(s_{2} \mid s^{t}\right) \frac{u_{C}\left(R^{1}\left(s^{t}, s_{2}\right)\right)}{\beta R^{1}\left(s^{t}, s_{2}\right) P\left(s^{t}, s_{2}\right)}+ \\
\ldots+\pi\left(s_{n} \mid s^{t}\right) \frac{u_{C}\left(R^{1}\left(s^{t}, s_{n}\right)\right)}{\beta R^{1}\left(s^{t}, s_{n}\right) P\left(s^{t}, s_{n}\right)}
\end{array}\right] \\
& \frac{u_{C}\left(R^{1}\left(s^{t}\right)\right)}{P\left(s^{t}\right)}=\beta^{3} R^{3}\left(s^{t}\right)\left[\begin{array}{c}
\pi\left(s_{1} \mid s^{t}\right) \frac{u_{C}\left(R^{1}\left(s^{t}, s_{1}\right)\right)}{\beta^{2} R^{2}\left(s^{t}, s_{1}\right) P\left(s^{t}, s_{1}\right)}+\pi\left(s_{2} \mid s^{t}\right) \frac{u_{C}\left(R^{1}\left(s^{t}, s_{2}\right)\right)}{\beta^{2} R^{2}\left(s^{t}, s_{2}\right) P\left(s^{t}, s_{2}\right)}+ \\
\ldots+\pi\left(s_{n} \mid s^{t}\right) \frac{u_{C}\left(R^{1}\left(s^{t}, s_{n}\right)\right)}{\beta^{2} R^{2}\left(s^{t}, s_{n}\right) P\left(s^{t}, s_{n}\right)}
\end{array}\right. \\
& \text {... } \\
& \frac{u_{C}\left(R^{1}\left(s^{t}\right)\right)}{P\left(s^{t}\right)}=\beta^{n} R^{n}\left(s^{t}\right)\left[\begin{array}{c}
\pi\left(s_{1} \mid s^{t}\right) \frac{u_{C}\left(R^{1}\left(s^{t}, s_{1}\right)\right)}{\beta^{n-1} R^{n-1}\left(s^{t}, s_{1}\right) P\left(s^{t}, s_{1}\right)}+\pi\left(s_{2} \mid s^{t}\right) \frac{u_{C}\left(R^{1}\left(s^{t}, s_{2}\right)\right)}{\beta^{n} R^{n-1}\left(s^{t}, s_{2}\right) P\left(s^{t}, s_{2}\right)}+ \\
\ldots+\pi\left(s_{n} \mid s^{t}\right) \frac{u_{C}\left(R^{1}\left(s^{t}, s_{n}\right)\right)}{\beta^{n-1} R^{n-1}\left(s^{t}, s_{n}\right) P\left(s^{t}, s_{n}\right)}
\end{array}\right]
\end{aligned}
$$

If $R^{j}\left(s^{t}\right), j=1, \ldots, n$ are set exogenously, for a given price level $P\left(s_{t}\right)$ these are $n$ equations in $n$ unknowns, $P\left(s^{t}, s_{j}\right), j=1, \ldots, n$. As long as there is enough variability in $R^{j}\left(s^{t}, s_{j}\right), j=1, \ldots, n$, that guarantees that the matrix of coefficients is invertible, there is a unique solution of the system of equations. For a given initial price level $P\left(s_{0}\right)$, there is a unique solution for the allocations and prices. 